\title{
Unconventional is not unpredictable
}

\section{Oil and gas industry experts met recently to discuss technological advances in the flourishing unconventional resource sector. Sam Green and Martyn Millwood Hargrave discovered that quantitative predictive approaches are reinvigorating the role of geoscience}

The oil and gas industry is starting to recover from a long downturn. A surge in exploration and production has been fuelled largely by the exploitation of unconventional reservoirs, such as shale gas. The Unconventional Resources Technology Conference (URTeC; http:// urtec.org/2018), held in Houston from 23 to 25 July 2018, encompasses all the many technologies involved in the burgeoning unconventional resources sector, including geoscience and subsurface engineering. This sixth annual assembly saw over 6,000 attendees, approximately double the number who attended in 2017, demonstrating the growth in interest in this uniquely focussed conference.

This year, more than any other previously, saw a significant number of presentations highlighting the value in building integrated, multi-disciplinary, sub-surface models and utilising technologies that allow for efficient and predictive data analysis, including the advance in data analytics using data science and machine learning. The talks highlighted the importance of being able to integrate data from multiple sources to build a coherent sub-surface model that captures the variation in multiple rock properties, lithology and kerogen, pore pressure and stress. Calibration of the seismic domain using sophisticated inversion prior to complex completion and hydraulic fracturing is proving crucial to effective exploration and exploitation of unconventional plays, particularly in the Delaware and Permian basins of Texas and New Mexico-the hot spot of world unconventional resources and very much the economic proving ground of new technologies.

\section{Geomechanical models}

There are many important factors that govern whether unconventional plays will be commercially successful or not. One that probably gathers the most focus is the fracturing characteristics of the rock itself. Building an accurate geomechanical model, one that defines the stress state (magnitude and azimuth) within any given interval, is critical to aid operators in the effective design of hydraulic fracturing programs. The topic of pore-pressure integration and, moreover, the ability to predict high pore pressure, received

a lot of attention in the conference talks and on the show floor. Pore pressure underpins geomechanical models because it is a critical input, and several talks showed the value in taking a quantitative approach to pore-pressure prediction, which was previously often based on mud weights that are now known to be too simplistic with respect to the true pore pressure. The other key element to geomechanical models is the ability to upscale, or apply, the models that were calibrated to the wells into the 3D seismic domain. Any rock physics or geomechanical model is dependent on the input parameters of compressional (Vp) and shear (Vs) seismic wave velocities, as well as density (Rho). However, the ability to accurately predict rock properties (facies, pressure, stress) away from the control wells is dependent on the accuracy of the seismic inversion, and accuracy can be reduced due to the presence of complex mixed facies. Fortunately, case studies presented at the conference used new technologies that allow for facies-dependent, elastic property volumes to be derived, leading to a significant increase in the accuracy and confidence of 3D geomechanical models.

\section{Big data}

Unconventional plays, in contrast to many conventional areas, have a large number of wells; there are tens of thousands of wells available across the Permian Basin, with up to a million more wells to be drilled over the next ten years. Analyses can be made from huge datasets, but the volume of data puts complete analysis beyond the capacity of the human interpreter. This is where the new domain of data science, underpinned by machine learning, can meaningfully help the industry.

Several presentations throughout the conference discussed this theme. The benefits were clear, focus on maximising value for the organisation by utilising machine learning to: build consistent petrophysical datasets saving human-years of time; quickly and reliably apply predictive models for key properties, such as facies, pressure, and stress, across all wells; aid in efficient drilling by classifying and avoiding drilling hazards; and chase new opportunities through missed play and missed pay identification.

After a fallow period for geoscience over the past few years, the key message from the conference was clear: new quantitative approaches to geoscience can add considerable economic value to unconventional operators by optimising well locations and enabling more cost-effective engineering and recovery.

\section{6 THE NEW DOMAIN OF DATA SCIENCE, UNDERPINNED BY MACHINE LEARNING, CAN MEANINGFULLY HELP THE INDUSTRY}

Sam Green is Lead Geologist at Ikon Science; e-mail: sgreen@ikonscience.com

Martyn Millwood Hargrave is the Executive Chairman of Ikon Science; e-mail: mmhargrave@ikonscience.com 